\title{
Predictors for complete obliteration of arteriovenous malformations following stereotactic radiosurgery
}

\author{
Zengpanpan $\mathrm{Ye}^{1, *}$, Xiaolin $\mathrm{Ai}^{1,{ }^{*}}$, Xin $\mathrm{Hu}^{1, *}$, Chao You ${ }^{1}$, Andrew Faramand ${ }^{2}$ and Fang \\ Fang $^{1}$ \\ ${ }^{1}$ Department of Neurosurgery, West China Hospital of Sichuan University, Chengdu, Sichuan, China \\ ${ }^{2}$ Department of Neurosurgery, University of Pittsburgh Medical Center, Pittsburgh, Pennsylvania, United States of America \\ *These authors contributed equally to this work
}

Correspondence to: Fang Fang, email: jipin_li@163.com

Keywords: arteriovenous malformation; radiosurgery; obliteration rate

Received: September 22, $2017 \quad$ Accepted: October 27, $2017 \quad$ Published: December 21, 2017

Copyright: Ye et al. This is an open-access article distributed under the terms of the Creative Commons Attribution License 3.0 (CC BY 3.0), which permits unrestricted use, distribution, and reproduction in any medium, provided the original author and source are credited.

\section{ABSTRACT}

Objective: Radiosurgery is one of the management options used to treat cerebral arteriovenous malformation (AVM). The primary goal of treatment is the complete obliteration of AVM. Multiple factors have been proposed predicting complete AVM obliteration. This meta-analysis aims to assess the predictors of complete obliteration following stereotactic radiosurgery.

Materials and Methods: A literature search was conducted using the databases PubMed, Cochrane Central Register of Controlled Trials and EMBASE. Articles discussing predictors of obliteration of AVM following radiosurgery were included. Odd ratio and $95 \%$ confidence intervals were used to assess the predictive ability of identified predictors.

Results: Higher obliteration rates were observed in previously ruptured AVM (OR: $1.21,95 \%$ CI, $1.02-1.43, p=0.03$ ), lower Spetzler-Martin grade (OR: $1.66,95 \%$ CI, 1.11-2.50, $p=0.01$ ), and in AVM receiving a higher marginal dose (OR: $1.18,95 \% \mathrm{CI}$, 1.11-1.24, $p<0.001$ ). In contrast, deep AVM location (OR: 0.51, 95\% CI, 0.39-0.67, $p<0.001$ ), eloquence (OR: 0.67, 95\% CI, 0.42-1.06, $p=0.09$ ), prior embolization (OR: $0.83,95 \%$ CI, $0.72-0.95, p=0.006$ ), larger target volume (OR: $0.82,95 \% \mathrm{CI}$, 0.71-0.95, $p=0.009$ ), and a higher Radiosurgery-based AVM score (RBAS) (OR: $0.48,95 \% \mathrm{CI}, 0.36-0.65, p<0.001$ ) were associated with lower obliteration rates.

Conclusions: A previously ruptured AVM, a lower Spetzler-Martin grade, a higher marginal dose, non-deep location, no prior embolization, smaller target volume, and lower RBAS were identified as positive predictors for obliteration. Particularly, patients with AVM categorized as having a lower RBAS, radiosurgery should be considered as a first management option for a higher obliteration rate. However, factors such as age, eloquence and sex were not found to influence obliteration rates.

\section{INTRODUCTION}

Cerebral arteriovenous malformation (AVM) represent an abnormal collection of arteries and veins without an intervening capillary bed [1]. High blood flow and elevated pressure increase the risk of rupture and subsequent hemorrhage. Ruptured AVM is a major cause of secondary intracranial hemorrhage. AVM rupture is associated with high mortality and morbidity rates,
$29 \%$ and $23 \%$, respectively [2-4]. Several therapeutic methods are used to treat AVM, including radiosurgery, embolization, surgical resection or combination of several methods [5]. Radiosurgery is being used more frequently, particularly in patients with surgically inaccessible lesions. Radiosurgery has been shown to be a low risk procedure that is associated with high obliteration rates [6-8]. The primary aim of radiosurgery is to prevent hemorrhage by achieving complete AVM obliteration. 
Once complete obliteration is identified on angiography, the overall risk of hemorrhage drops to $1 \%$ [9]. However, an interval period exists from the time of radiosurgery until complete obliteration is achieved, during which the risk of hemorrhage remains. Proper selection of patients undergoing radiosurgery is paramount in predicting success of radiosurgery. Multiple factors have been proposed as positive predictors for complete AVM obliteration such as the volume of AVM [10-12] and history of prior embolization [11, 13-15]. However, some inconsistencies exist in the literature. For instance, some reports $[15,16]$ suggested a high predictive ability (odds ratio: 1.4) of prior embolization for complete obliteration, while other studies $[10,11,13,14]$ demonstrated no significant difference in obliteration rates with or without prior embolization.

Therefore, we conducted a meta-analysis to evaluate the factors predicting complete obliteration which will help identify the patients with a higher chance of complete obliteration following stereotactic radiosurgery.

\section{RESULTS}

\section{Literature research}

A total of 926 articles were available from the electronic databases, of which 31 articles were selected after reviewing the titles and abstracts. Six-hundred and seventy (670) unrelated articles were excluded. After reviewing the full texts of the 31 selected articles, 10 articles [10-16, 19-21] met the inclusion criteria and where selected for the analysis. From the selected articles, 10 predictive factors were identified and subsequently analyzed, including rupture of AVM, deep location, noneloquence, craniotomy surgery, prior embolization, volume of AVM, max diameter, gender, age, and high margin dose.

\section{Characteristics of included studies}

Ten retrospective studies with 2280 patients were included in this analysis (Table 1). The majority of the included articles where conducted between 2012 and 2017. Three studies were conducted in North America, two studies were done in Asia, and six studies were done in Europe. The mean of age ranged from 33 to 40 years. The mean radiosurgery-based arteriovenous malformation score (RBAS) was about 1.4 in all included studies, and the mean of margin dose utilized ranged from 15 to 25 Gy. Complete obliteration rate ranged between 59\% and $87 \%$. AVM obliteration was identified using CTA, MRA or DSA. All analyzed studies had a high quality with a NOS score $>6$.

\section{Rupture of AVM}

Four studies [10, 11, 13, 14] including 1346 patients presented AVM rupture as a predictor for obliteration.
After pooling the data of these studies with fixed-effect model, ruptured AVM demonstrated higher obliteration rates than unruptured AVM, with pooled OR of 1.21 (95\% CI, 1.02-1.43, $p=0.03$, Figure 1A). There was no significant heterogeneity between these studies $(p=0.32$ and $\mathrm{I}^{2}=14 \%$ ).

\section{Deep location}

Two studies [10, 14] of 826 subjects reported the association between AVM location (basal ganglia, thalamus, or brainstem) and obliteration. These two studies showed a negative association between deep location and obliteration with multivariate logistic regression, and had no significant heterogeneity ( $p=0.28$ and $\left.\mathrm{I}^{2}=15 \%\right)$. Using fixed-effect model analysis, the pooled results suggested that deep AVM location was associated with a lower obliteration rate (OR: $0.51,95 \%$ CI, 0.39-0.67, $p<$ 0.001, Figure 1B).

\section{Eloquent AVM}

In four studies [11, 13, 14, 20] of 1302 patients, the pooled OR of eloquent cortex AVM location for obliteration was 0.67 (95\% CI, 0.42-1.06, $p=0.09)$. With sensitivity analysis, the high heterogeneity ( $p=0.04$ and $\mathrm{I}^{2}=65 \%$ ) was attributed to the study by Pollock [14], and the random-effects model was used. After excluding the study by Pollock, the heterogeneity significantly decreased $\left(p=0.32\right.$ and $\left.\mathrm{I}^{2}=13 \%\right)$ and AVM located in the eloquent location were associated with lower obliteration rates (OR: $0.55,95 \%$ CI, $0.37-$ $0.84, p=0.005$, Figure 1C). The subgroup analysis by techniques showed that the pooled OR of eloquent cortex AVM location for obliteration was 0.64 (95\% CI, 0.43-0.96, $p=0.03$ ) in the LINAC group, while no association was found in Gama Knife group with OR of 1.02 (95\% CI, 0.78-1.33, $p=0.89)$.

\section{Prior resection}

Two studies [11, 14] including 801 subjects reported an association between prior surgical resection and obliteration rates. There was no significant heterogeneity ( $p=0.33$ and $\mathrm{I}^{2}=0 \%$ ) and the fixedeffects model was used. After pooling the ORs of two studies and 801 subjects, the results showed that the prior craniotomy surgery was not associated with a higher obliteration rate (OR: 1.19, 95\% CI, 0.82-1.73, $p=0.37$, Figure 1D).

\section{Prior embolization}

There were six studies [10, 11, 13-16] of 1625 subjects reporting the OR and 95\% CI for the relationship between prior embolization and AVM 
Table 1: Characteristic of included articles

\begin{tabular}{|c|c|c|c|c|c|c|c|c|c|c|c|c|c|}
\hline Author & Year & Country & Study design & $\begin{array}{l}\text { Patients } \\
\quad(n)\end{array}$ & $\begin{array}{l}\text { Sex } \\
(\mathbf{M} / \mathbf{F})\end{array}$ & $\begin{array}{c}\text { Mean } \\
\text { age } \\
\text { (years) }\end{array}$ & $\begin{array}{l}\text { Mean } \\
\text { RBVS }\end{array}$ & Techniques & $\begin{array}{c}\text { Mean } \\
\text { dose } \\
\text { (Gy) }\end{array}$ & $\begin{array}{l}\text { Study } \\
\text { period }\end{array}$ & $\begin{array}{c}\text { Obliteration } \\
(\%)\end{array}$ & $\begin{array}{l}\text { Detection of } \\
\text { obliteration }\end{array}$ & $\begin{array}{l}\text { NOS } \\
\text { score }\end{array}$ \\
\hline Thenier-Villa, J. L. & 2017 & Spain & Retrospective & 195 & $110 / 85$ & 37.6 & 1.70 & LINAC & 16.75 & $\begin{array}{l}1998- \\
2013\end{array}$ & 81 & $\begin{array}{l}\text { DSA or } \\
\text { MRA }\end{array}$ & 8 \\
\hline Pollock, B. E. & 2016 & USA & Retrospective & 381 & $169 / 212$ & 39.5 & 1.37 & GK & 19.2 & $\begin{array}{l}1990- \\
2009\end{array}$ & 85 & $\begin{array}{l}\text { DSA or } \\
\text { MRA }\end{array}$ & 9 \\
\hline Paul, L. & 2014 & Spain & Retrospective & 662 & $362 / 300$ & 37.1 & / & GK & 18.9 & $\begin{array}{l}1993- \\
2005\end{array}$ & 71 & $\begin{array}{l}\text { DSA or } \\
\text { MRA }\end{array}$ & 8 \\
\hline $\begin{array}{c}\text { Hattangadi-Gluth, } \\
\text { J. A. }\end{array}$ & 2014 & USA & Retrospective & 248 & $124 / 124$ & 39 & 1.33 & $\begin{array}{l}\text { Proton beam } \\
\text { linac }\end{array}$ & 15 & $\begin{array}{l}1991- \\
2010\end{array}$ & 70 & $\begin{array}{l}\text { MRA or } \\
\text { CTA }\end{array}$ & 7 \\
\hline Fokas, E. & 2013 & Germany & Retrospective & 164 & $89 / 75$ & 36 & 1.41 & LINAC & 19 & $\begin{array}{l}1998- \\
2008\end{array}$ & 61 & MRA & 7 \\
\hline Taeshineetanakul, P. & 2012 & Canada & Retrospective & 139 & $75 / 64$ & 35.5 & 1.30 & $\begin{array}{l}\text { LINAC and } \\
\text { GK }\end{array}$ & 18.8 & $\begin{array}{c}2000- \\
2009\end{array}$ & 69 & $\begin{array}{l}\text { DSA or } \\
\text { MRA }\end{array}$ & 8 \\
\hline Kano, H. & 2012 & China & Retrospective & 120 & $61 / 59$ & 33 & 1.43 & GK & 18 & $\begin{array}{l}1987- \\
2006\end{array}$ & 59 & $\begin{array}{l}\text { DSA or } \\
\text { MRA }\end{array}$ & 8 \\
\hline Cetin, I. A. & 2012 & Turkey & Retrospective & 92 & $49 / 43$ & 35 & 1.36 & $\begin{array}{l}\text { Proton beam } \\
\text { linac }\end{array}$ & 20 & $\begin{array}{c}2000- \\
2006\end{array}$ & 80 & $\begin{array}{l}\text { DSA or } \\
\text { MRA }\end{array}$ & 7 \\
\hline Zabel, A & 2005 & Germany & Retrospective & 110 & $50 / 60$ & 40 & / & LINAC & 18 & $\begin{array}{c}1998- \\
2001\end{array}$ & 87 & $\begin{array}{c}\text { CTA, MRA } \\
\text { and DSA }\end{array}$ & 7 \\
\hline Schlienger, M & 2000 & France & Retrospective & 169 & $62 / 107$ & 33 & I & LINAC & 25 & $\begin{array}{c}1990- \\
1993\end{array}$ & 64 & $\begin{array}{l}\text { DSA or } \\
\text { MRA }\end{array}$ & 7 \\
\hline
\end{tabular}

RBAS: radiosurgery-based arteriovenous malformation score; LINAC: linear accelerator; GK: Gamma knife.

obliteration. In two studies, prior embolization was associated with lower obliteration rates, while in the remaining four studies, no such association was identified. The fixed-effects model was used and found no significant heterogeneity $\left(p=0.12\right.$ and $\left.\mathrm{I}^{2}=43 \%\right)$. The results suggested that prior embolization significantly reduces obliteration rates (OR: $0.83,95 \% \mathrm{CI}, 0.72-0.95$, $p=0.006$, Figure 1E).

\section{Target volume}

Three studies [10-12] of 395 patients presented the OR of the relationship between higher target volume and obliteration rate. All of these studies suggested that a higher target volume was associated with lower the obliteration rate. Two studies $[11,12]$ suggested the cutoff values of target volume at $4 \mathrm{ml}$ and $8 \mathrm{ml}$. The pooled OR of higher target volume for obliteration was 0.82 (95\% CI, $0.71-0.95, p=0.009$, Figure $1 \mathrm{~F}$ ) by a random-effects model $\left(p=0.14\right.$ and $\left.\mathrm{I}^{2}=50 \%\right)$.

\section{Spetzler-martin (SM) grade}

The Spetzler-Martin grade was considered an independent predictor in two studies of 334 patients $[11,19]$. These studies showed the patients with a lower SM grade (I, II and III) had a higher obliteration rate than higher SM grade (IV and V). After pooling the results, there was no heterogeneity $\left(p=0.95\right.$ and $\left.\mathrm{I}^{2}=0 \%\right)$ between the two studies and the AVM with lower SM grade was associated with a higher obliteration rate (OR: 1.66, 95\% CI, $1.11-2.50, p=0.01$, Figure $1 \mathrm{G}$ ).

\section{Radiosurgery-based arteriovenous malformation score $(R B A S)$}

Three studies [10, 11, 15] of 413 patients presented the OR for the relationship between RBAS and obliteration rates. Two $[10,15]$ of these studies demonstrated that AVM with lower RBAS had a higher obliteration rates. One study [11] found no such association. For the heterogeneity of these studies $\left(p=0.13\right.$ and $\mathrm{I}^{2}=51 \%$ ), the random-effects model was conducted and the results suggested the higher RBAS was associated with a lower obliteration rate (OR: $0.48,95 \%$ CI, 0.36-0.65, $p<0.001$, Figure 1H). The subgroup analysis by techniques suggested the pooled OR of higher RBAS for obliteration was $0.42(95 \% \mathrm{CI}, 0.34-0.52, p<0.01)$ in the proton beam linac group, but no significance in LINAC group (OR: $0.75,95 \% \mathrm{CI}, 0.45-1.25, p=0.27$ ).

\section{Gender}

The ORs and 95\% CIs for relationship between gender and obliteration were reported in six studies of 1548 subjects [10-15]. There was no difference in obliteration rate between males and females (OR: 1.04, $95 \%$ CI, $0.90-1.20, p=0.63$, Figure 1I). For the significant heterogeneity $\left(p=0.24\right.$ and $\left.\mathrm{I}^{2}=26 \%\right)$, the fixed-effects model was used.

Age

Five studies [10, 11, 13-15] of 1456 patients included analyzed the relationship between age at the 
time of radiosurgery and the obliteration rate. Only one study [15] showed that an older age was associated with the lower obliteration rate, while the remaining studies found that there was no difference. The pooled results also showed there was no difference in patients with different age (OR: 1.00, 95\% CI, 0.99-1.01, $p=0.90$, Figure $1 \mathrm{~J}$ ), without significant heterogeneity $\left(p=0.16\right.$ and $\mathrm{I}^{2}=38 \%$ ).

\section{High marginal dose}

The ORs and 95\% CIs of marginal dose utilized and obliteration were reported in seven studies of 1254 subjects [10-13, 15, 20, 21]. A higher marginal dose was associated with higher obliteration rates (OR: 1.22, $95 \%$ CI, 1.11-1.34, $p<0.001$, Figure $1 \mathrm{~K})$. For the heterogeneity $\left(p=0.06\right.$ and $\left.\mathrm{I}^{2}=51 \%\right)$, the random-effects model was used and the study by Cetin [15] was found to be the origin of the heterogeneity. After excluding the study by Cetin, the heterogeneity decreased ( $p=0.66$ and $\left.\mathrm{I}^{2}=0 \%\right)$ and the higher marginal dose was still a predictor for higher obliteration rate (OR: $1.18,95 \%$ CI, $1.11-$ $1.24, p<0.001)$. The subgroup analysis by techniques suggested that higher marginal dose was associated with higher obliteration rates in the proton beam linac group (OR: 1.47, 95\% CI, 1.11-1.93, $p=0.006$ ), LINAC group (OR: $1.20,95 \%$ CI, 1.09-1.32, $p<0.001$ ) and Gama Knife group (OR: 1.17, 95\% CI, 1.10-1.26, $p<0.001$ ).

\section{Publication bias}

Begg's test conducted by STATA 13.0 also showed no evidence of publication bias ( $p=0.764$, Figure 2$)$ for higher marginal dose, which involved the largest number of articles.

\section{DISCUSSION}

\section{Implications}

The primary goal of treatment for AVM is the complete obliteration of the AVM, so that the risk of hemorrhage is eliminated [9]. Thus, identifying of the factors associated with higher obliteration rates is important. To the best of our knowledge, this is the first meta-analysis performed that looks at the positive predictors for obliteration of AVM following radiosurgery. The obliteration rates of AVM following radiosurgery range between $59 \%$ and $87 \%[12,19]$. After pooling the results of ten articles with 2280 patients, we found that lower obliteration rates were reported in patients with unruptured AVM, AVM located in deep cerebral locations, prior embolization, larger AVM volume, a higher SM grade or RBAS, and a lower marginal dose.

Multiple reports $[22,23]$ have suggested that ruptured AVM are associated with higher obliteration rates. This is thought to be related to better visualization of the nidus following AVM rupture, thus making it easier to target the AVM with radiosurgery [22, 23]. Three $[10,11,13]$ of the four analyzed studies looking at the association between AVM rupture and concluded that a trend towards higher obliteration rates in previously ruptured AVM exists. However, Ding et al. [22] showed the ruptured AVM had significantly higher complete obliteration rates $(68 \%)$ than the unruptured AVM (48\%) using univariate logistic regression. Pooling the data from the four studies with minimal heterogeneity demonstrated higher obliteration rates in previously ruptured AVM. The inconsistencies observed could be attributed to limited number of patients included in the analyzed studies.

AVMs located in deep locations, such as the thalamus, brainstem, or basal ganglia, are associated with high rates of mortality and morbidity [24]. Moreover, deep AVM are reported to have lower obliteration rates after radiosurgery [10, 25-27]. Hattangadi-Gluth et al. [10] reported an obliteration rate of $62 \%$ in AVM located in deep structures. In contrast, the obliteration rates of AVM located in other locations was 67\%. Pollock et al. [14] also reported the deeply located AVM had lower complete obliteration rates compared to those located in the cerebral hemispheres or the cerebellum $(77.8 \%$ VS $86.5 \%$ at 8 years), which was consistent with our findings.

Some researches $[11,13,14,20]$ looked at whether obliteration rates varied depending on the eloquent location of the AVM. An eloquent location refers to highly functional cortical areas of the brain such as the sensorimotor, language, or visual cortex [14]. Ding et al. [28] demonstrated that $28 \%$ of AVM located in eloquent areas were completely obliterated 5 years after radiosurgery, which was significantly lower than the obliteration rates of AVM located in noneloquent areas (43\%). The result of LINAC group were also consistent with these studies, while there was no association of eloquent location and obliteration in Gama Knife group.

SM grade was initially proposed to determine the operative risks in patients undergoing surgery for AVM [29]. The factors considered in the grading system are size of nidus, the type of venous drainage (superficial vs deep) and the location of AVM in terms of eloquence. Obliteration rates reported following radiosurgery for SM grades I and II range between $80 \%$ and $93 \%$ [9, 30]. The obliteration rates following radiosurgery for SM grades III ranged from $60 \%$ to $72 \%[22,23]$. Obliteration rates for SM grades IV and V are reported to be around 43.6\% [31]. Although two studies $[11,19]$ showed that there was no association between the SM grade and obliteration rate, we found that AVM with lower SM grade had a higher obliteration rate. This may be related a smaller AVM volume observed in lower SM grade [21]. Although the SM grade could be an independent predictor for obliteration, RBAS had a stronger predictive ability than SM grade, with OR of 2.08 and 1.66 respectively. The RBAS [32] was generally used to predict the obliteration rate. The criteria utilized includes age, location and the 
A

Study or Subgroup

Fokas, E. 2013

Hattangadi-Gluth, J. A. 2014

Pollock, B. E. 2016

Thenier-Villa, J. L. 2017

Odds Ratio

Odds Ratio

log[Odds Ratio] SE Weight IV, Fixed, 95\% Cl

$\begin{array}{llll}0.3436 & 0.2523 & 11.7 \% & 1.41[0.86,2.31]\end{array}$

$\begin{array}{llll}0.27 & 0.1586 & 29.7 \% & 1.31[0.96,1.79]\end{array}$

$\begin{array}{llll}0.077 & 0.1162 & 55.2 \% & 1.08[0.86,1.36]\end{array}$

$\begin{array}{llll}0.8372 & 0.4697 & 3.4 \% & 2.31\end{array}[0.92,5.80]$

Total $(95 \% \mathrm{Cl})$

$100.0 \%$

$1.21[1.02,1.43]$

Heterogeneity: $\mathrm{Chi}^{2}=3.47, \mathrm{df}=3(\mathrm{P}=0.32) ; \mathrm{l}^{2}=14 \%$

Test for overall effect: $Z=2.21(P=0.03)$

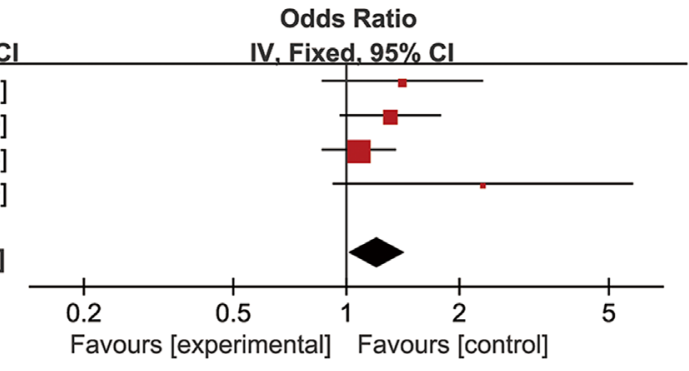

B

Odds Ratio Odds Ratio

Study or Subgroup

log[Odds Ratio] SE Weight IV. Fixed. $95 \% \mathrm{Cl}$

IV. Fixed. $95 \% \mathrm{Cl}$

Hattangadi-Gluth, J. A. 2014

Pollock, B. E. 2016

$\begin{array}{lll}-0.8675 & 0.2254\end{array}$

$\begin{array}{ll}-0.5621 & 0.1681\end{array}$

$35.7 \%$

$64.3 \%$

Total $(95 \% \mathrm{Cl})$

$100.0 \% \quad 0.51[0.39,0.67]$

Heterogeneity: $\mathrm{Chi}^{2}=1.18, \mathrm{df}=1(\mathrm{P}=0.28) ; \mathrm{I}^{2}=15 \%$

Test for overall effect: $Z=4.98(P<0.00001)$

$0.42[0.27,0.65]$

$0.57[0.41,0.79]$

C

Study or Subgroup

Pollock, B. E. 2016

Taeshineetanakul, P. 2012

Thenier-Villa, J. L. 2017

log[Odds Ratio]

$\begin{array}{rrr} & \text { SE } & \text { Weight } \\ -0.3857 & 0.2338 & 29.8 \% \\ 0.0198 & 0.1369 & 36.9 \%\end{array}$

$\begin{array}{rrr}0.0198 & 0.1369 & 36.9 \% \\ -1.1632 & 0.4634 & 16.1 \%\end{array}$

$\begin{array}{lll}-0.6524 & 0.4374 & 17.2 \%\end{array}$

Total $(95 \% \mathrm{Cl})$

$100.0 \%$

Heterogeneity: $\mathrm{Tau}^{2}=0.13 ; \mathrm{Chi}^{2}=8.57, \mathrm{df}=3(\mathrm{P}=0.04) ; \mathrm{I}^{2}=65 \%$

Test for overall effect: $Z=1.72(P=0.09)$

Random. 95\% Cl

$0.68[0.43,1.08]$

$1.02[0.78,1.33]$

$0.31[0.13,0.77]$

$0.52[0.22,1.23]$

$0.67[0.42,1.06]$

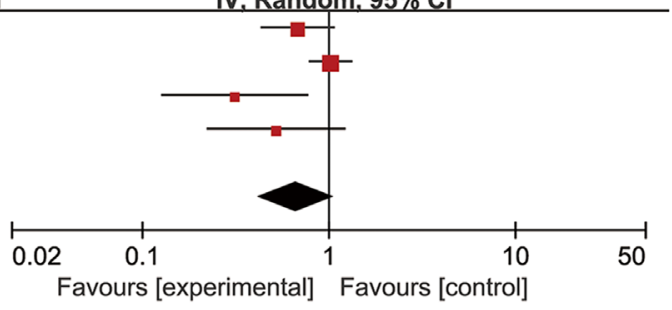

D

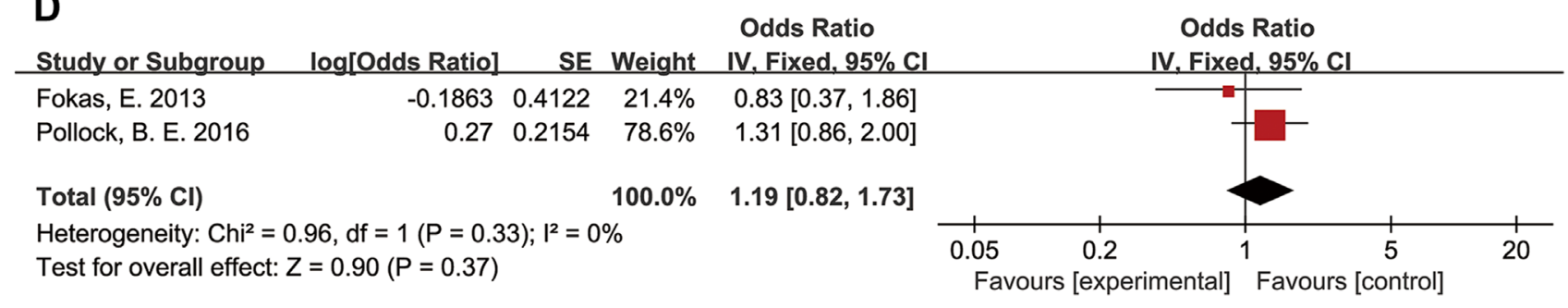

E

Study or Subgroup

Odds Ratio

IV. Fixed, $95 \% \mathrm{Cl}$

Cetin, I. A. 2012

log[Odds Ratio] SE Weight

$\begin{array}{lll}-0.3638 & 0.1194 & 34.2 \%\end{array}$

$\begin{array}{lll}-0.1165 & 0.2456 \quad 8.1 \%\end{array}$

Hattangadi-Gluth, J. A. 2014

$\begin{array}{lll}-0.1985 & 0.3281\end{array}$

$4.5 \%$

$\begin{array}{lll}-0.3711 & 0.3044 \quad 5.3 \%\end{array}$

$\begin{array}{lll}-0.7133 & 0.3233 & 4.7 \%\end{array}$

$0.01 \quad 0.1063 \quad 43.2 \%$

Thenier-Villa, J. L. 2017

$100.0 \%$

Total $(95 \% \mathrm{Cl})$

$0.70[0.55,0.88]$

$0.89[0.55,1.44]$

$0.82[0.43,1.56]$

$0.69[0.38,1.25]$

$0.49[0.26,0.92]$

$1.01[0.82,1.24]$

Heterogeneity: $\mathrm{Chi}^{2}=8.72, \mathrm{df}=5(P=0.12) ;\left.\right|^{2}=43 \%$

Test for overall effect: $Z=2.74(P=0.006)$

$0.83[0.72,0.95]$

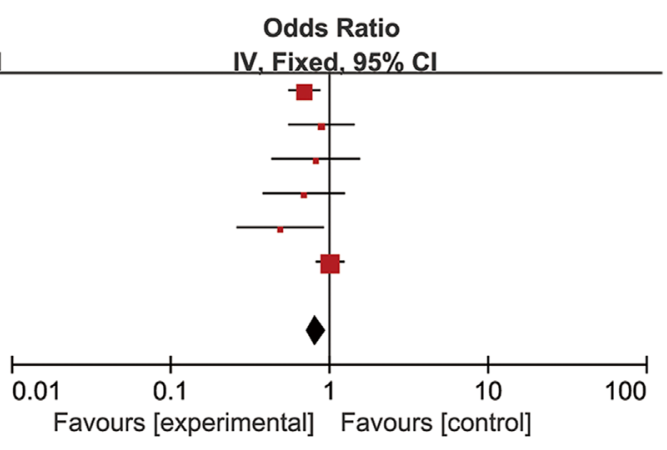

$\mathbf{F}$

Study or Subgroup

Fokas, E. 2013

Hattangadi-Gluth, J. A. 2014

log[Odds Ratio] SE Weight

Kano, H. 2012

$\begin{array}{lll}-0.5933 & 0.2447 \quad 8.3 \%\end{array}$

$\begin{array}{lll}-0.2107 & 0.0893 \quad 34.6 \%\end{array}$

$\begin{array}{lll}-0.1301 & 0.0392 \quad 57.1 \%\end{array}$

Total $(95 \% \mathrm{Cl})$

$100.0 \%$

Heterogeneity: $\mathrm{Tau}^{2}=0.01 ; \mathrm{Chi}^{2}=4.00, \mathrm{df}=2(\mathrm{P}=0.14) ; \mathrm{I}^{2}=50 \%$

Test for overall effect: $Z=2.61(P=0.009)$

Random, 95\% C

$0.55[0.34,0.89]$

$0.81[0.68,0.96]$

$0.88[0.81,0.95]$

$0.82[0.71,0.95]$

Favours [experimental] Favours [control]

Favours [experimental] Favours [control]

IV. Random, $95 \% \mathrm{Cl}$ 
G

Odds Ratio

Odds Ratio

Study or Subgroup log[Odds Ratio] SE Weight IV, Fixed, 95\% Cl

Fokas, E. 2013

$\begin{array}{llll}0.4941 & 0.328 & 39.7 \% & 1.64[0.86,3.12]\end{array}$

Zabel, A. 2005

0.520 .2663

$60.3 \%$

$1.68[1.00,2.83]$

Total $(95 \% \mathrm{CI})$

$100.0 \% \quad 1.66[1.11,2.50]$

Heterogeneity: $\mathrm{Chi}^{2}=0.00, \mathrm{df}=1(\mathrm{P}=0.95) ; \mathrm{I}^{2}=0 \%$

Test for overall effect: $Z=2.47(P=0.01)$

IV. Fixed, $95 \% \mathrm{Cl}$

H

\begin{tabular}{lrrr} 
Study or Subgroup & log[Odds Ratio] & SE & Weight \\
\hline Cetin, I. A. 2012 & -0.858 & 0.1598 & $38.2 \%$ \\
Fokas, E. 2013 & -0.2877 & 0.2606 & $22.6 \%$ \\
Hattangadi-Gluth, J. A. 2014 & -0.8675 & 0.1549 & $39.2 \%$ \\
& & & \\
Total (95\% Cl) & & $100.0 \%$ \\
Heterogeneity: Tau & $=0.04 ;$ Chi $^{2}=4.12$, df $=2(P=0.13) ; I^{2}=51 \%$ \\
Test for overall effect: $Z=4.78(P<0.00001)$ &
\end{tabular}

Odds Ratio

Random, 95\% Cl

$0.42[0.31,0.58]$

$0.75[0.45,1.25]$

$0.42[0.31,0.57]$

$0.48[0.36,0.65]$

Test for overall effect: $Z=4.78(P<0.00001)$

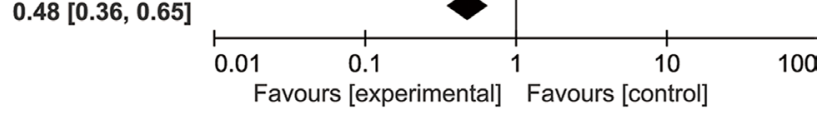

I

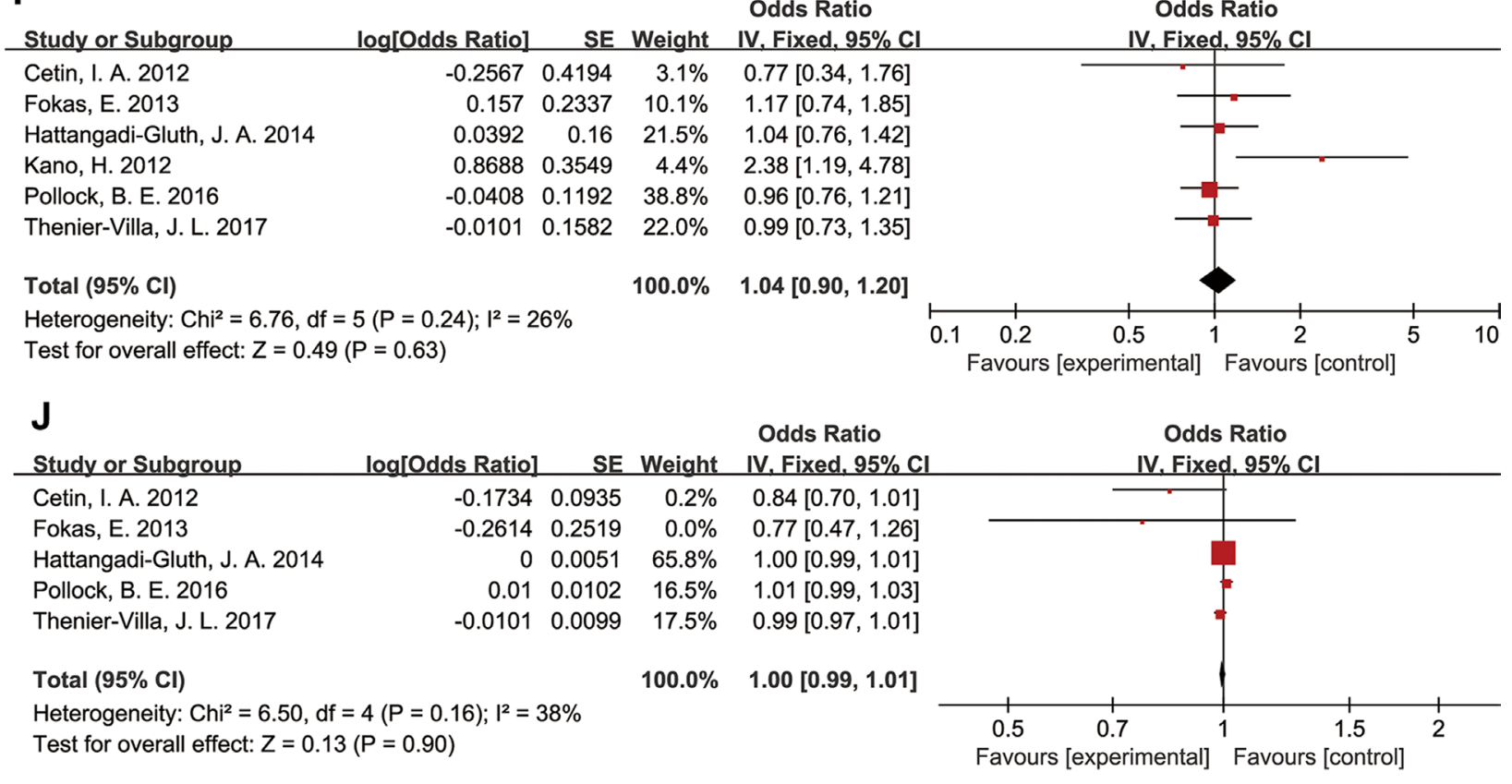

K

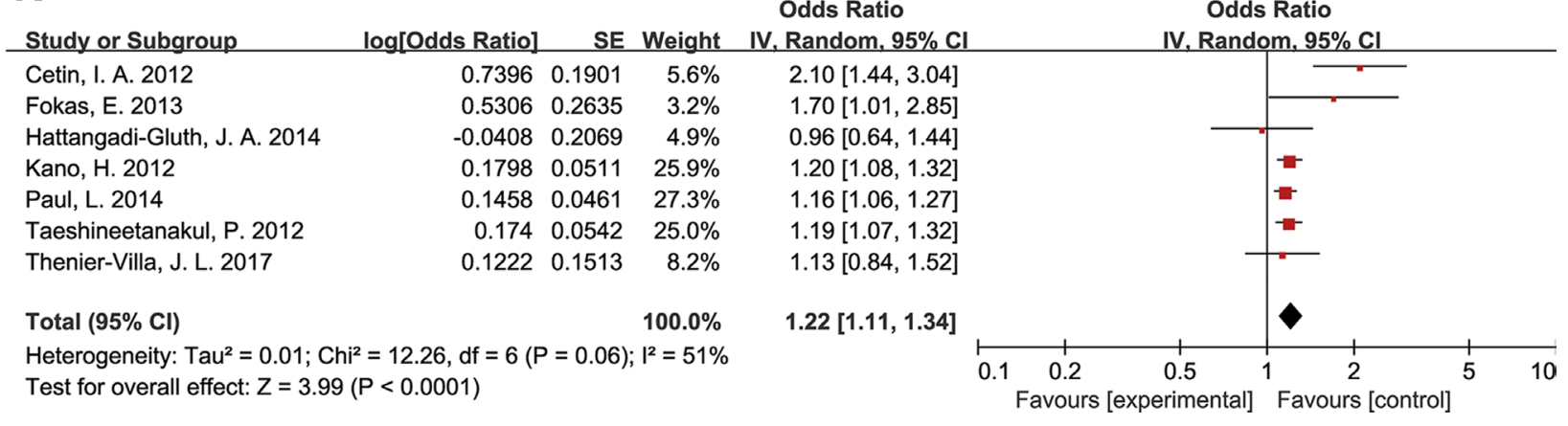

Figure 1: Forest plots for relationship between obliteration rates and rupture of AVM (A), deep cerebral locations (B), eloquent locations $(\mathbf{C})$, prior resection $(\mathbf{D})$, prior embolization $(\mathbf{E})$, larger AVM volume $(\mathbf{F})$, lower SM grade $(\mathbf{G})$ or RBAS $(\mathbf{H})$, gender $(\mathbf{I})$, age $(\mathbf{J})$ and lower marginal dose $(\mathbf{K})$. 
size of AVM. Patients with RBAS of $0.01-1.50,1.51-$ 2.00 and $>2.00$ had obliteration rates of $63 \%, 60 \%$ and $28 \%$, respectively [11]. We found that a higher RBAS had the highest predictive ability of all the factors with OR of 2.08 for complete obliteration, however, the included studies did not provide cut-off values of RBAS that can be used to identify patients with the best chance of complete obliteration following radiosurgery. Moreover, we found the higher RBAS predicted the obliteration in the proton beam linac group, but not in LINAC group. For only one study in LINAC group, the prediction of RBAS in patients with LINAC treatment needs more studies to evaluate in future.

Few studies discussed the effect of surgical resection on the outcomes following radiosurgery. The two studies $[11,14]$ suggested the prior surgery had no influence on obliteration rate, and analysis demonstrated similar results. However, the effect embolization on obliteration was assessed in many articles. Cetin et al. and Schlienger et al. $[15,16]$ demonstrated that previously embolized AVM were significantly less likely to obliterate compared to unembolized AVM (54\% VS $71 \%$, respectively). Three articles [10, 11, 14] demonstrated a trend towards lower obliteration rates in previously embolized AVM, however, there results didn't reach statistical significance. Embolization could result in making the nidus more diffuse, making targeting the nidus at the time of radiosurgery more difficult [21]. However, Zabel-du et al. [33] suggested that the AVM of $\geq 3 \mathrm{~cm}$ in diameter had lower obliteration rates than AVM with a smaller diameter $<3 \mathrm{~cm}(92 \%$ VS $60 \%)$. Izawa et al. [34] demonstrated that following AVM embolization, radiosurgery for malformations $12 \mathrm{~mm}^{3}$ or larger where more likely to obliterate compared to lesions less than $12 \mathrm{~mm}^{3}$ in $90 \%$ vs $10 \%$, respectively. We found that prior embolization was associated with lower complete obliteration rates in patients following radiosurgery. Thus, it is important to appropriately choose patients undergoing embolization prior to radiosurgery so that the benefits of embolization outweigh the risks associated with lower obliteration rate.

Target volume was considered as an independent predictor for obliteration in many studies [10-12]. Fokas [11] suggested that AVM with a target volume smaller than $4 \mathrm{cc}$ would have a higher complete obliteration rate, while Kano [12] showed the cut-off was between 6 and $8 \mathrm{~mm}^{3}$ with univariate analysis. Another study [35] demonstrated that the complete obliteration rates were $67 \%, 58 \%$ and $23 \%$ in treatment volumes of $<4 \mathrm{~mm}^{3}, 4-14 \mathrm{~mm}^{3}$ and $>$ $14 \mathrm{~mm}^{3}$, respectively.

Kano et al. [12] found that females were more likely to have complete obliteration compared to males, with a HR of 2.384. The remaining studies [10, 11, 13-15] did not find such a correlation. Moreover, we

\section{Begg's funnel plot with pseudo 95\% confidence limits}

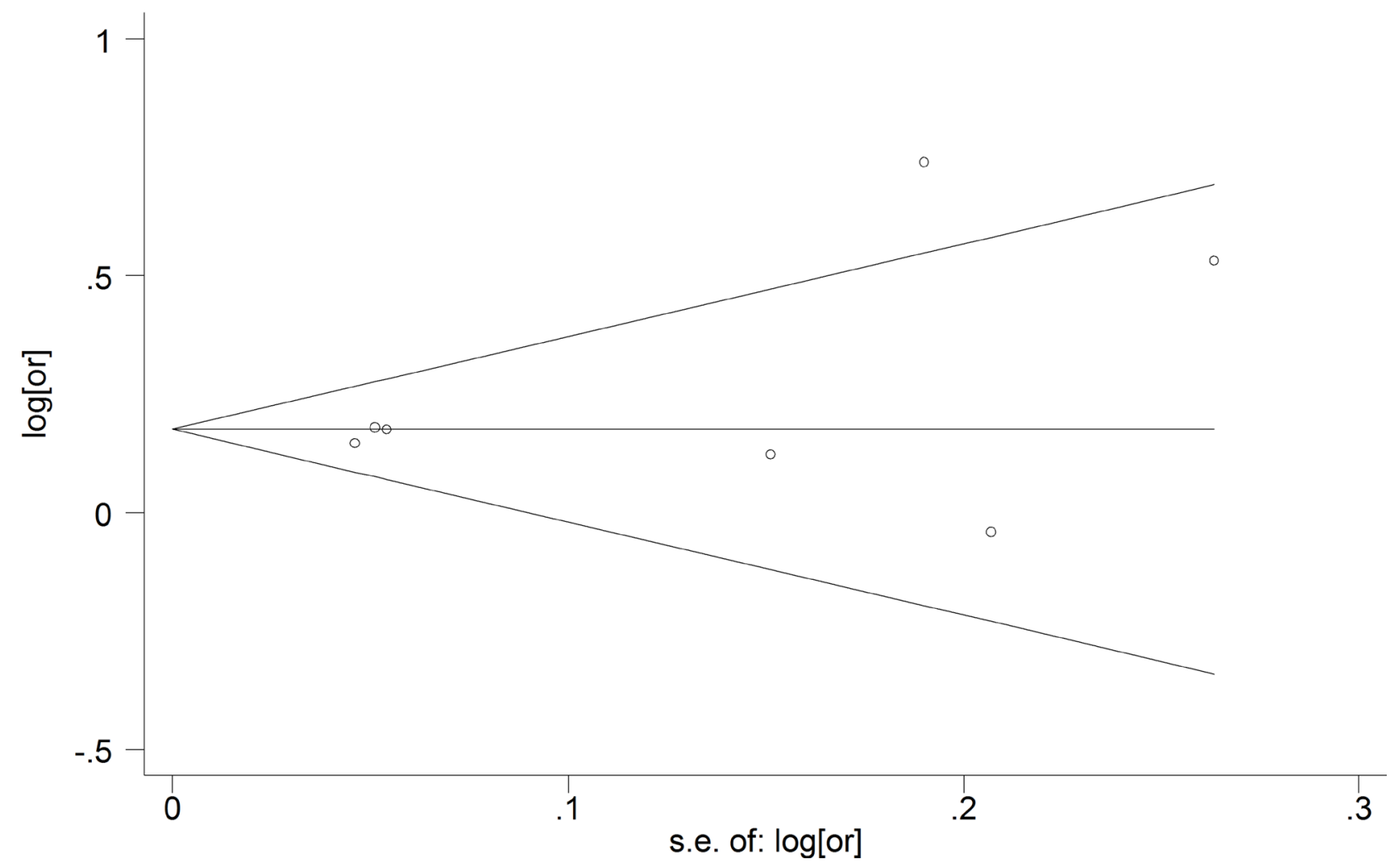

Figure 2: The Begg publication bias plot of the studies reporting the association of obliteration rate and higher marginal dose with $P=0.764$. 
found no significant association between gender and obliteration.

The margin dose commonly ranged from 16 to 25 Gy, and almost all of the included studies that higher obliteration rates are achieved by utilizing higher margin doses. Our results also showed higher margin doses were associated with higher obliteration rates, regardless of the techniques (proton beam linac, LINAC OR Gama Knife). However, margin doses higher than 25 Gy were associated with minimal effects on obliteration rates, while also being associated with higher rates of adverse radiation effects [36]. Kano et al. [12] suggested a cutoff value of margin dose of $18 \mathrm{~Gy}$ with OR of 1.197. Although Cetin et al. [15] suggested 20Gy as the cut-off value with OR of 2.09. More evidence is still required to set the margin dose that is associated with the highest obliteration rates and the lowest risk of adverse radiation effects.

\section{Limitation}

The included articles were all retrospective studies, which might result in the selection bias and the highquality studies are needed. Several factors influencing clinical outcomes, such as post-radiosurgery hemorrhage and radiation-induced changes, were not covered in the report. However, the assessment of factors for complete obliteration, the major aim of radiosurgery, was necessary to identify the patients with a higher chance of favorite outcomes following radiosurgery. Appropriate patient selection prior to radiosurgery would improve the outcomes. Third, for the limited data, we could not identify the factors affecting the interval of time from first radiosurgery to complete obliteration.

\section{MATERIALS AND METHODS}

\section{Collect the eligible articles}

This study was performed following the Preferred Reporting Items for Systematic Reviews and MetaAnalyses (PRISMA) guidelines (Figure 3). A literature search was conducted using the search engines PubMed, Cochrane Central Register of Controlled Trials and EMBASE from the beginning of indexing to Sep 12, 2017 using the keywords: obliteration, arteriovenous malformations and radiosurgery. The reference of included articles were checked to find additional related studies.

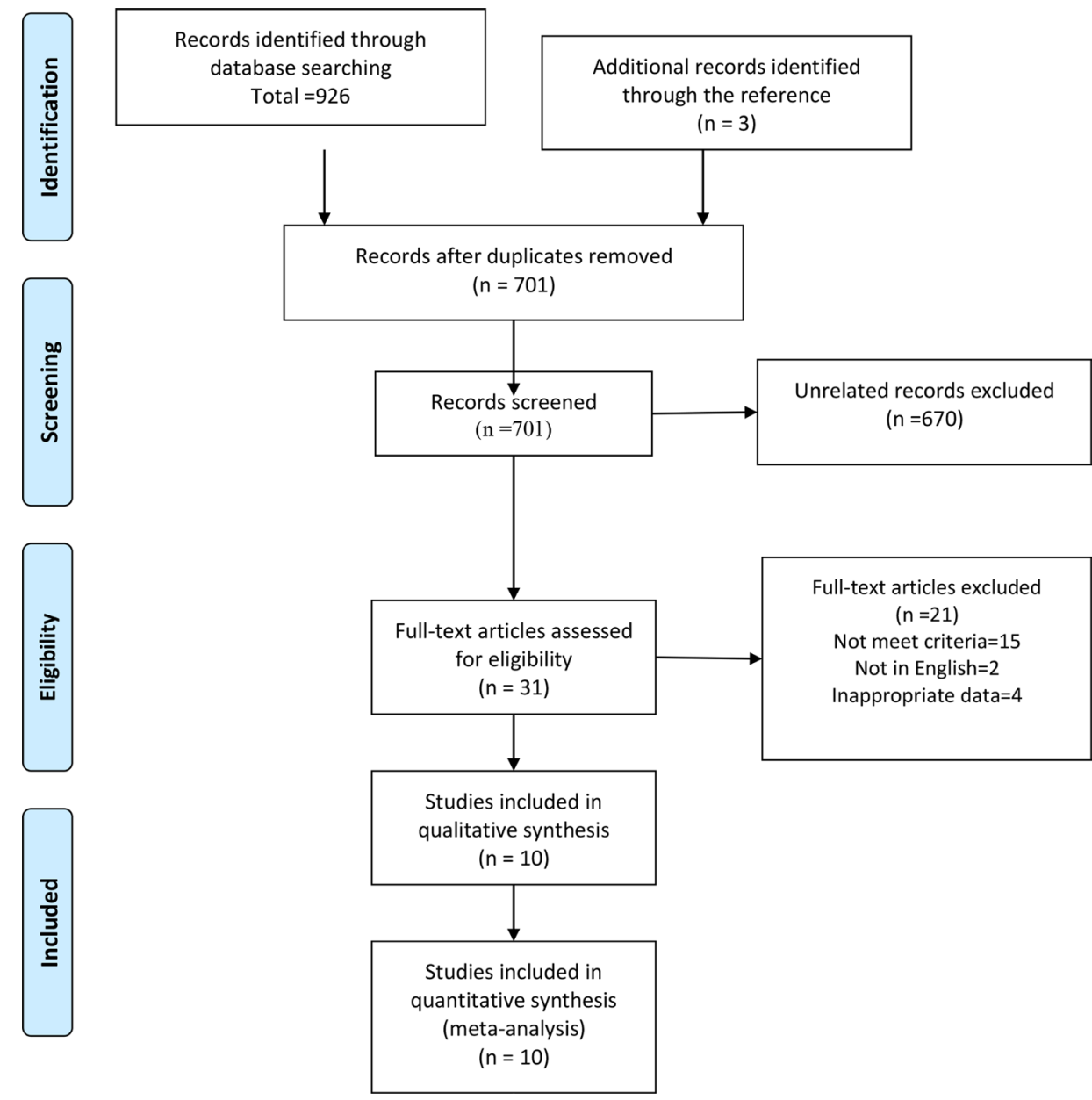

Figure 3: The flow diagram of procedures to search the included studies. 


\section{Inclusion and exclusion criteria}

Initial review consisted of reviewing the titles and abstracts of all available studies. The full texts of selected studies where independently reviewed by two neurosurgeons. The eligibility of the selected studies and disagreements were discussed. The inclusion criteria consisted of: 1-Studies reporting on patients diagnosed with intracerebral AVMs and treated with radiosurgery; 2 - Studies which had the odds ratio (OR) and $95 \%$ CI of variables for the obliteration available, or the original data included is sufficient to calculate the OR and $95 \% \mathrm{CI}$; 3- Case-control, cohort studies or randomized controlled studies (RCTs) were included. Articles reporting outcomes of radiosurgery for AVM in children, articles not in English, case reports, and animal studies were excluded.

\section{Data extraction}

The data from the included studies were extracted by two authors independently and the disagreements were discussed. The following data were extracted from eligible studies: author, year of publication, country, study design, number of patients, gender, study period, rate of obliteration, detection method, year of follow up, and the ORs and $95 \%$ CI of variables for obliteration. Obliteration of AVM identified by Computed Tomography Angiography (CTA), Magnetic Resonance Angiography (MRA) or Digital Subtraction Angiography (DSA) was considered the end points. The techniques of radiosurgery included linear accelerator (LINAC), Gamma Knife, and proton beam linac. The values of multivariate regression analysis were first choice when the ORs of univariate regression analysis and multivariate regression analysis coexisted.

\section{Quality assessment of the included articles}

The quality of the included studies were evaluated by two authors independently using the Newcastle-Ottawa Scale (NOS) [17]. The score ranged from 0 to 9 points. The quality of study was considered high if the score was higher than 6 points.

\section{Data analysis}

The software Review Manager Version 5.3 (Cochrane collaboration, Oxford, UK) was used to pool the OR of the variables for obliteration, and the STATA 13.0 (STATA Corporation, College Station, TX) was used to assess the publication bias of the included studies. The pooled ORs and $95 \%$ CIs were used to evaluate the efficiency of variables for obliteration. The fixed-effects would be used when the heterogeneity was not significant with the $\mathrm{I}^{2}<50 \%$ or $p>0.10$, otherwise, the randomeffects would be used. The sensitivity analysis was used to confirm the robustness of the pooled results in analysis with significant heterogeneity [18]. The subgroup analysis by different techniques of radiosurgery would be conducted if there was a significant heterogeneity $\left(\mathrm{I}^{2}>\right.$ $50 \%$ or $p<0.10$ ) between the included studies. Funnel plot with Begg rank correlation was used to assess the publication bias of included studies. If $p>0.05$, there was no significant difference.

\section{CONCLUSIONS}

The results of this meta-analysis suggest that unruptured AVM, deep location, prior embolization, higher target volume, higher SM grade or RBAS, and lower marginal dose were associated with lower complete obliteration rate. RBAS had the highest predictive ability in present study, and more studies are required to evaluate the optimal cut-off score of RBAS for complete obliteration. However, age, eloquent location and gender were not a predictor for complete obliteration in patients with AVMs.

\section{ACKNOWLEDGMENTS}

None.

\section{CONFLICTS OF INTEREST}

\author{
No conflicts of interest.
}

\section{FUNDING}

This work is supported by Science and technology supportive project of Sichuan Province. Project: Intracerebral haemorrhage prevention and diagnostic treatment skills (No. 2015SZ0051); Outstanding subject development 135 project: An international, multicenter, large sample randomized controlled trial of supratentorial deep intracerebral haematoma surgery and conservative treatment in adults (No. ZY2016102); and the projects of National Natural Science Foundation of China (contract/ grant number: 81100925, 81472361).

\section{REFERENCES}

1. Lawton MT, Rutledge WC, Kim H, Stapf C, Whitehead KJ, Li DY, Krings T, terBrugge K, Kondziolka D, Morgan MK, Moon K, Spetzler RF. Brain arteriovenous malformations. Nat Rev Dis Primers. 2015; 1: 15008. https://doi. org/10.1038/nrdp.2015.8.

2. Brown RD Jr, Wiebers DO, Forbes G, O'Fallon WM, Piepgras DG, Marsh WR, Maciunas RJ. The natural history of unruptured intracranial arteriovenous malformations. J Neurosurg. 1988; 68:352-7. https://doi.org/10.3171/ jns.1988.68.3.0352.

3. Perret G, Nishioka H. Report on the cooperative study of 
intracranial aneurysms and subarachnoid hemorrhage. Section VI. Arteriovenous malformations. An analysis of 545 cases of cranio-cerebral arteriovenous malformations and fistulae reported to the cooperative study. J Neurosurg. 1966; 25:467-90. https://doi.org/10.3171/ jns.1966.25.4.0467.

4. Stapf C, Labovitz DL, Sciacca RR, Mast H, Mohr JP, Sacco $\mathrm{RL}$. Incidence of adult brain arteriovenous malformation hemorrhage in a prospective population-based stroke survey. Cerebrovasc Dis. 2002; 13:43-6.

5. Gross BA, Du R. Diagnosis and treatment of vascular malformations of the brain. Curr Treat Options Neurol. 2014; 16: 279. https://doi.org/10.1007/s11940-013-0279-9.

6. Karlsson B, Lindquist C, Steiner L. Prediction of obliteration after gamma knife surgery for cerebral arteriovenous malformations. Neurosurgery. 1997; 40:42530; discussion 30-1.

7. Yamamoto M, Jimbo M, Hara M, Saito I, Mori K. Gamma knife radiosurgery for arteriovenous malformations: long-term follow-up results focusing on complications occurring more than 5 years after irradiation. Neurosurgery. 1996; 38:906-14.

8. Yamamoto M, Jimbo M, Kobayashi M, Toyoda C, Ide M, Tanaka N, Lindquist C, Steiner L. Long-term results of radiosurgery for arteriovenous malformation: neurodiagnostic imaging and histological studies of angiographically confirmed nidus obliteration. Surg Neurol. 1992; 37:219-30.

9. Kano H, Lunsford LD, Flickinger JC, Yang HC, Flannery TJ, Awan NR, Niranjan A, Novotny J Jr, Kondziolka D. Stereotactic radiosurgery for arteriovenous malformations, Part 1: management of Spetzler-Martin Grade I and II arteriovenous malformations. J Neurosurg. 2012; 116:1120. https://doi.org/10.3171/2011.9.JNS101740.

10. Hattangadi-Gluth JA, Chapman PH, Kim D, Niemierko A, Bussiere MR, Stringham A, Daartz J, Ogilvy C, Loeffler JS, Shih HA. Single-fraction proton beam stereotactic radiosurgery for cerebral arteriovenous malformations. Int J Radiat Oncol Biol Phys. 2014; 89:338-46. https://doi. org/10.1016/j.ijrobp.2014.02.030.

11. Fokas E, Henzel M, Wittig A, Grund S, Engenhart-Cabillic R. Stereotactic radiosurgery of cerebral arteriovenous malformations: long-term follow-up in 164 patients of a single institution. J Neurol. 2013; 260:2156-62. https://doi.org/10.1007/s00415-013-6936-9.

12. Kano H, Kondziolka D, Flickinger JC, Park KJ, Iyer A, Yang HC, Liu X, Monaco EA 3rd, Niranjan A, Lunsford LD. Stereotactic radiosurgery for arteriovenous malformations after embolization: a case-control study. J Neurosurg. 2012; 117:265-75. https://doi.org/10.3171/2012.4.jns111935.

13. Thenier-Villa JL, Galarraga-Campoverde RA, Martinez Rolan RM, De La Lama Zaragoza AR, Martinez Cueto P, Munoz Garzon V, Salgado Fernandez M, Conde Alonso C. Linear Accelerator Stereotactic Radiosurgery of Central Nervous System Arteriovenous Malformations: A 15-Year
Analysis of Outcome-Related Factors in a Single Tertiary Center. World Neurosurg. 2017; 103:291-302. https://doi. org/10.1016/j.wneu.2017.04.081.

14. Pollock BE, Link MJ, Stafford SL, Garces YI, Foote RL. Stereotactic Radiosurgery for Arteriovenous Malformations: The Effect of Treatment Period on Patient Outcomes. Neurosurgery. 2016; 78:499-509. https://doi.org/10.1227/ neu.0000000000001085.

15. Cetin IA, Ates R, Dhaens J, Storme G. Retrospective analysis of linac-based radiosurgery for arteriovenous malformations and testing of the Flickinger formula in predicting radiation injury. Strahlenther Onkol. 2012; 188:1133-8. https://doi.org/10.1007/s00066-012-0180-6.

16. Schlienger $\mathrm{M}$, Atlan $\mathrm{D}$, Lefkopoulos $\mathrm{D}$, Merienne L, Touboul E, Missir O, Nataf F, Mammar H, Platoni K, Grandjean P, Foulquier JN, Huart J, Oppenheim C, et al. Linac radiosurgery for cerebral arteriovenous malformations: results in 169 patients. Int J Radiat Oncol Biol Phys. 2000; 46:1135-42.

17. Stang A. Critical evaluation of the Newcastle-Ottawa scale for the assessment of the quality of nonrandomized studies in meta-analyses. European Journal of Epidemiology. 2010; 25:603-5. https://doi.org/10.1007/s10654-010-9491-z.

18. Patsopoulos NA, Evangelou E, Ioannidis JP. Sensitivity of between-study heterogeneity in meta-analysis: proposed metrics and empirical evaluation. Int J Epidemiol. 2008; 37:1148-57. https://doi.org/10.1093/ije/dyn065.

19. Zabel A, Milker-Zabel S, Huber P, Schulz-Ertner D, Schlegel W, Debus J. Treatment outcome after linac-based radiosurgery in cerebral arteriovenous malformations: retrospective analysis of factors affecting obliteration. Radiother Oncol. 2005; 77:105-10. https://doi.org/10.1016/j.radonc.2005.04.008.

20. Taeshineetanakul P, Krings T, Geibprasert S, Menezes R, Agid R, Terbrugge KG, Schwartz ML. Angioarchitecture determines obliteration rate after radiosurgery in brain arteriovenous malformations. Neurosurgery. 2012; 71:1071-8; discussion 9. https://doi.org/10.1227/NEU.0b013e31826f79ec.

21. Paul L, Casasco A, Kusak ME, Martinez N, Rey G, Martinez R. Results for a series of 697 arteriovenous malformations treated by gamma knife: influence of angiographic features on the obliteration rate. Neurosurgery. 2014; 75:568-83; dicussion 82-3; quiz 83. https://doi. org/10.1227/neu.0000000000000506.

22. Ding D, Yen CP, Starke RM, Xu Z, Sun X, Sheehan JP. Radiosurgery for Spetzler-Martin Grade III arteriovenous malformations. J Neurosurg. 2014; 120:959-69. https://doi. org/10.3171/2013.12.JNS131041.

23. Kano H, Flickinger JC, Yang HC, Flannery TJ, Tonetti D, Niranjan A, Lunsford LD. Stereotactic radiosurgery for Spetzler-Martin Grade III arteriovenous malformations. J Neurosurg. 2014; 120:973-81. https://doi. org/10.3171/2013.12.JNS131600.

24. Fleetwood IG, Marcellus ML, Levy RP, Marks MP, Steinberg GK. Deep arteriovenous malformations 
of the basal ganglia and thalamus: natural history. J Neurosurg. 2003; 98:747-50. https://doi.org/10.3171/ jns.2003.98.4.0747.

25. Starke RM, Yen CP, Ding D, Sheehan JP. A practical grading scale for predicting outcome after radiosurgery for arteriovenous malformations: analysis of 1012 treated patients. J Neurosurg. 2013; 119:981-7. https://doi. org/10.3171/2013.5.JNS1311.

26. Andrade-Souza YM, Zadeh G, Ramani M, Scora D, Tsao MN, Schwartz ML. Testing the radiosurgery-based arteriovenous malformation score and the modified Spetzler-Martin grading system to predict radiosurgical outcome. J Neurosurg. 2005; 103:642-8. https://doi. org/10.3171/jns.2005.103.4.0642.

27. Flores GL, Sallabanda K, dos Santos MA, Gutierrez J, Salcedo JC, Beltran C, Fernandez CP, Atienza MG, Samblas J. Linac stereotactic radiosurgery for the treatment of small arteriovenous malformations: lower doses can be equally effective. Stereotact Funct Neurosurg. 2011; 89:338-45. https://doi.org/10.1159/000330837.

28. Ding D, Yen CP, Xu Z, Starke RM, Sheehan JP. Radiosurgery for primary motor and sensory cortex arteriovenous malformations: outcomes and the effect of eloquent location. Neurosurgery. 2013; 73:816-24; discussio 24. https://doi.org/10.1227/NEU.0000000000000106.

29. Spetzler RF, Martin NA. A proposed grading system for arteriovenous malformations. J Neurosurg. 1986; 65:47683. https://doi.org/10.3171/jns.1986.65.4.0476.

30. Ding D, Yen CP, Xu Z, Starke RM, Sheehan JP. Radiosurgery for low-grade intracranial arteriovenous malformations. J Neurosurg. 2014; 121:457-67. https://doi. org/10.3171/2014.1.JNS131713.

31. Ding D, Yen CP, Starke RM, Xu Z, Sun X, Sheehan JP. Outcomes following single-session radiosurgery for highgrade intracranial arteriovenous malformations. $\mathrm{Br} \mathrm{J}$ Neurosurg. 2014; 28:666-74. https://doi.org/10.3109/0268 8697.2013.872227.
32. Pollock BE, Flickinger JC. Modification of the radiosurgery-based arteriovenous malformation grading system. Neurosurgery. 2008; 63:239-43; discussion 43. https://doi.org/10.1227/01.NEU.0000315861.24920.92.

33. Zabel-du Bois A, Milker-Zabel S, Huber P, Schlegel W, Debus J. Risk of hemorrhage and obliteration rates of LINAC-based radiosurgery for cerebral arteriovenous malformations treated after prior partial embolization. Int J Radiat Oncol Biol Phys. 2007; 68:999-1003. https://doi. org/10.1016/j.ijrobp.2007.01.027.

34. Izawa M, Chernov M, Hayashi M, Iseki H, Hori T, Takakura $\mathrm{K}$. Combined management of intracranial arteriovenous malformations with embolization and gamma knife radiosurgery: comparative evaluation of the long-term results. Surg Neurol. 2009; 71:43-52; discussion 52-3. https://doi.org/10.1016/j.surneu.2007.11.016.

35. Miyawaki L, Dowd C, Wara W, Goldsmith B, Albright N, Gutin P, Halbach V, Hieshima G, Higashida R, Lulu B, Pitts L, Schell M, Smith V, et al. Five year results of LINAC radiosurgery for arteriovenous malformations: outcome for large AVMS. Int J Radiat Oncol Biol Phys. 1999; 44:1089106.

36. Flickinger JC, Kondziolka D, Maitz AH, Lunsford LD. An analysis of the dose-response for arteriovenous malformation radiosurgery and other factors affecting obliteration. Radiother Oncol. 2002; 63:347-54. 